\title{
UTILIZATION OF SENTINEL-2 IMAGERY IN THE ESTIMATION OF PLASTICS AMONG FLOATING DEBRIS ALONG THE COAST OF MANILA BAY
}

\author{
M.L. R. Gonzaga ${ }^{1 *}$, M. T. S. Wong ${ }^{1 *}$, A. C. Blanco ${ }^{1,2}$, J. A. Principe ${ }^{1,2}$ \\ ${ }^{1}$ Department of Geodetic Engineering, University of the Philippines Diliman, Quezon City - *(mrgonzaga, mswong)@up.edu.ph \\ ${ }^{2}$ Training Center for Applied Geodesy and Photogrammetry, University of the Philippines Diliman, Quezon City -
} (acblanco, japrincipe)@up.edu.ph

KEY WORDS: Sentinel-2, plastic, remote sensing, MTMF, Naive-Bayes.

\begin{abstract}
:
With the Philippines ranking as the third largest source of plastics that end up in the oceans, there is a need to further explore methodologies that will become an aid in plastic waste removal from the ocean. Manila Bay is a natural harbor in the Philippines that serves as the center of different economic activities. However, the bay is also threatened with plastic pollution due to increasing population and industrial activities. BASECO is one of the areas in Manila Bay where clean-up activities are focused as this is where trash accumulates. Sentinel-2 images are provided free of charge by the European Commission's Copernicus Programme. Satellite images from June 2019 to May 2020 were inspected, then cloud-free images were downloaded. After downloading and pre-processing, spectral data of different types of plastic such as shipping pouch, bubble wrap, styrofoam, PET bottle, sando bag and snack packaging that were measured by a spectrometer during a fieldwork by the Development of Integrated Mapping, Monitoring, and Analytical Network System for Manila Bay and Linked Environments (project MapABLE) were utilized in the selection of training data. Then, indices such as the Normalized Vegetation Index (NDVI), Floating Debris Index (FDI) and Plastic Index (PI) from previous studies were analyzed for further separation of classes used as training data. These training data served as an input to the two supervised classification methods, Naive Bayes and Mixture Tuned Matched Filtering (MTMF). Both methods were validated by reports and articles from Philippine agencies indicating the spots where trash frequently accumulates.
\end{abstract}

\section{INTRODUCTION}

\subsection{Background of the Study}

Plastics have been studied and explored since 1284. As stated by ACS (1993), Dr. Leo Baekland's invention of synthetic plastic in 1907 has opened doors leading to the Age of Plastic, an industry that was able to employ 60 million people and more. After World War II, the people produced it on a massive scale. The convenience and efficiency of the use of plastic are undeniable. From 1950-2015, the annual production of plastic has increased to 381 million tonnes according to Ritchie (2018). In 2015, the Philippines was ranked as the 3rd largest source of plastic that ended up in the oceans. Annually, the Philippines contributes $\sim 0.28-0.75$ million tons of plastic into the marine environment (Jambeck et al., 2015), making the country one of the most significant contributors of plastic waste to the ocean (Lebreton et al., 2017). Jambeck et al (2015) showed that $81 \%$ of plastic waste in the Philippines is inadequately managed. This means that the disposal of wastes was not managed properly and done in uncontrolled landfills that are not contained fully. Inadequately managed plastic waste has a high risk of polluting bodies of water such as the ocean and river. Pasig River has ranked 8 out of 20 top polluting rivers in a study conducted by Lebreton (2017) which estimated the river contributing 38,800 tonnes of plastic wastes to oceans annually. More clean-up drives are being implemented in polluted bodies of water. It is important to eliminate macroplastic debris since it may harm marine organisms through entanglement or ingestion and eventually being degraded into microplastics. The problem with plastic pollution has existed for years, however, there is little information that is available with regards to plastic wastes monitoring due to the limited resources and studies in the Philippines. Finding a way to identify and classify macroplastic in floating debris using satellite data will contribute to easier management and planning of plastic waste removal from the oceans. The ability of remote sensing to provide uniform and wide coverage areas will help stakeholders identify areas with plastic pollution efficiently and lower expenses.

\subsection{Review of Related Literature}

Marine Pollution has been a problem all over the world for many years. According to NOAA, $80 \%$ of pollution stems from the land. An example of a pollutant is marine debris, which may range from microplastics, dilapidated fishing equipment, and poorly managed waste to deserted fishing vessels (NOAA, 2020). These pollutants may travel through drainages, rivers, and sewage to make their way into the ocean (Kukreja, 2020). Natural phenomena such as rain may also wash street litter into the waterways connected to the ocean (Marine Litter Solutions, 2020). There are also instances that humans leave their litter near the shore (World Ocean Review, 2010). The plastics that come from various sources accumulate at some locations in Manila Bay which may harm the marine life that are currently thriving in it as well as the people utilizing the bay.

Despite established laws regarding waste management, plastic pollution is still a problem in the Philippines. Clean-up efforts are one of the projects being conducted by different agencies. However, according to MBEMP (2002), these activities are costly. It may also be labour-intensive and requires a lot of resources. Current research methodologies are also focused on the in situ identification of plastics. Hence, there is a significant need to further explore the methodologies on how to identify these plastics and quantify them in a more efficient manner. 
The Department of Environmental and Natural Resources (DENR) identified Bataan Shipyard and Engineering Company (BASECO) as one of the most polluted parts of Manila Bay. According to a report by Manila's Department of Public Service, 53 metric tons of garbage can be found in BASECO every day. A report by World Vision's Waste to Wages Project (2019) stated that more than 70 metric tons of polyester type plastics in BASECO are collected in a span of one year. Clean-up activities are being spearheaded by DENR and other agencies. These activities are usually conducted along the stretch of the beach. Detection of floating plastic in BASECO will be done by utilizing Sentinel 2 images which are free to the public and readily available. This study aims to apply recent methodologies on the use of Remote Sensing in the identification of potential sites suffering from plastic pollution through the utilization of opensource satellite images in order to contribute to the small number of studies regarding local marine debris in the Philippines. An example of recent methodology is from a study by Biermann et al. (2020) from which they have utilized the satellite images from Sentinel-2 to detect floating patches in different countries like Ghana, Vietnam, United Kingdom, and Canada. Another study that has examined the capability of Sentinel-2 satellite images to detect floating plastic litter was done by Themistocleus, et al. (2020) in Limassol, Cyprus. With the aid of an unmanned aerial vehicle (UAV) that has acquired aerial images of the study area at the same time as the Sentinel-2 satellite overpass, Themistocleous et al. (2020) were able to identify the floating plastics on the surface of the water.

Estimating these floating plastics will help stakeholders locate which areas have a concentration of plastic pollution and plan accordingly on how to address this in order to lessen the plastic pollution that threatens the waters of Manila Bay. The study intends that the methodology used will be helpful for various sectors and government agencies in the country to aid in the monitoring of marine pollution. Proper monitoring of the country's bodies of water will eventually lead to better policy making and law implementation that aims to conserve and protect these resources.

\subsection{Study Area}

The study is focused on determining the plastics from floating debris found in the study area through the use of Sentinel 2 satellite imagery. The study area will only cover the Bataan Shipyard and Engineering Company (BASECO) area since this part of Manila Bay is where clean-up activities are focused. An additional criterion in choosing this area is the accessibility of drone images, which were used as a reference since field work was not possible during this time. As seen from the drone images from project MapABLE, this area of Manila Bay has visible pollution. Urban poor communities often face the challenge of segregating waste at point source due to its population density and the unavailability of facilities for the purpose of efficient waste collection and recovery (Plastic Bank, 2020).

The satellite images were retrieved from Sentinel-2 online through the ESA Copernicus website. Spectral data of plastics provided by Project MapABLE are limited to shipping pouch, bubble wrap, styrofoam, PET bottle, sando bag and snack packaging. Analysis of these values, along with indices from previous studies, was performed to create the training data. This means that the creation of training data would rely on the indices and the spectral library used since there is no field data available. The training data were used for the supervised classification using the Naive Bayes and Mixture Tuned Matched Filtering algorithm. The classification results are limited to qualitative validation based on reports from different agencies.

\section{METHODOLOGY}

\subsection{Data}

2.1.1 Data Acquisition (Satellite Image): A study by Biermann et al. (2020), aimed to find patches of debris in the ocean using Sentinel 2 satellite data. Floating macroplastics were identified among these patches through the use of developed indices and spectral analysis. Similarly, in this case, Sentinel 2 images for the Manila Bay area were downloaded from the European Space Agency's online website for the Sentinel 2 satellite. According to the Space Agency, Sentinel 2 satellite carries a multi-spectral sensor that produces 13 spectral bands. Level 1-C products of this satellite that contain top of the atmosphere reflectance values were used in this study.

According to the Philippine Atmospheric, Geophysical and Astronomical Services Administration (2015), the country's climate is divided into two categories. From June to November, the season is rainy, while from December to May, the corresponding season is dry. The dates of the satellite images downloaded is from June 2019 to May 2020 to cover the two major seasons in the Philippines, while taking into account the cloud coverage on the corresponding date. Table 1 summarizes the satellite images available and downloaded. For June to September of 2019, and November to December 2019, there were no satellite images downloaded due to the high percentage of cloud cover and the nature of some sensing dates being corrupted. For 2020, there was no available data for the month of February.

\begin{tabular}{|c|c|}
\hline Sensing Date & Type \\
\hline October 5, 2019 & 2B \\
\hline January 28, 2020 & 2A \\
\hline March 28, 2020 & 2A \\
\hline April 7, 2020 & 2A \\
\hline May 7, 2020 & 2A \\
\hline May 22, 2020 & 2B \\
\hline
\end{tabular}

Table 1. Downloaded Sentinel-2 satellite images.

2.1.2 Data Acquisition (Drone Image): Drone images that were flown on the area of BASECO beach and some parts of Pasig River were collected. The location of these images was identified within the downloaded Sentinel 2 images. The drone images were taken on November 19, 2020 and served as a reference for the approximate location of the plastics along the study area.

2.1.3 Data Acquisition (Spectral Data): A field study conducted by Project MapABLE resulted in a collection of spectral information on the different types of plastics that can be found around the study area. The spectral reflectances of different types of plastics such as shipping pouch, bubble wrap, styrofoam, PET bottle, sando bag and snack packaging were measured using a spectrometer. The graph in Fig. 1 shows the reflectance values of each plastic per wavelength in nanometers. These raw spectral reflectance may be affected by the material's surface roughness, angle of the sunlight, and its chemical and physical state (Jain \& Singh, 2003, p.132), hence, the spectral reflectance should be smoothed. Smoothed values were used to identify pixels with values that correspond to the spectral library. 


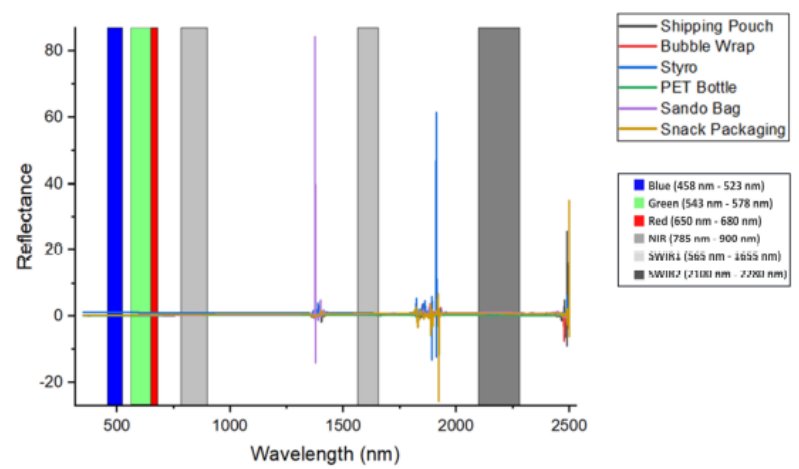

Figure 1. Raw spectral reflectance curves for various types of plastic wastes.

Biermann (2020) showed that plastics such as fishing nets, bottles, and plastic bags tend to reflect in the NIR, which makes it spectrally separable from water. Moroni et al. (2015) rendered the visible region of the spectrum inefficient for differentiation PVC and PET bottles since the reflectance values are dependent on colors. The study relied on the NIR region instead. Due to the variations of plastic litter in Manila Bay, this might explain the weak reflectance in the red, green and blue bands of the visible spectrum as seen in Fig. 1.

2.1.4 Creation of Training Data: The values for each generated index were analysed to separate the plastics from other materials. Through the utilization of the raster calculator, the reflectance values for Band 11 with $2202 \mathrm{~nm}$ as central wavelength showed potential plastics floating on the water. After the analysis of the index maps for the Normal Vegetation Difference Index, Floating Debris Index, and Plastic Index, a decision tree was constructed as shown in Fig. 2 for the creation of training data.

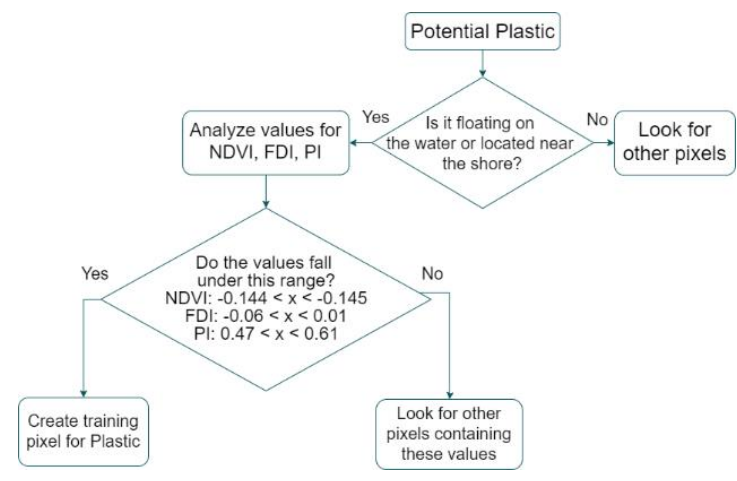

Figure 2. Decision tree for selecting training data for the Plastic class.

A decision tree was also constructed for the creation of the training data for water as shown in Fig. 3 since it can affect the reflectance of plastic in the NIR to SWIR region. According to Kou et al. (1993), the light that is reflected by wet materials may be decreased due to the high pure water absorption coefficient. In 2018, Garaba and Dierssen indicated that SWIR features may be masked by some factors such as water absorption, causing a median band depth index reduction when dry plastics are compared with wet plastics.

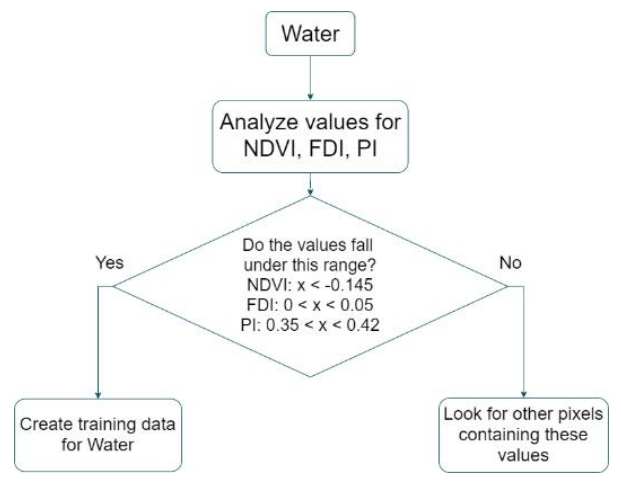

Figure 3. Decision tree for selecting training data for the Water class.

The decision trees were utilized for the creation of training data. As for the other classes such as the Built-Up, they were visually inspected since these features are easily identifiable. For each satellite image date, a new group of training data was created since the plastics are expected to be carried away by the water current, hence its location is not fixed throughout the year.

\subsection{Methods}

2.2.1 Image Pre-processing: According to Goddijn-Murphy et al. (2018), if the NIR to SWIR wavelengths were conserved during the atmospheric correction, these may be used to detect floating materials in Sentinel 2. Atmospheric Corrections were done using the Atmospheric Correction for OLI lite version 20210114.0 (ACOLITE). This correction used a "dark spectrum fitting" approach which provided straightforward processing for inland and coastal waters (Vanhellemont and Ruddick, 2018). The pre-processed image has been used in the NDVI and FDI indices. On the other hand, the image where the Plastic Index was generated did not undergo an atmospheric correction process.

2.2.2 Spectral Data Smoothing: Spectral data measurements may be subject to fluctuations in the signal or noise. Different techniques are used in smoothing spectral plots by removing the noise. According to Ruffin and King (1999), Savitzky-Golay filter is a technique that is used to reduce noise while maintaining higher order moments from the original spectral data. This filter is also known as the digital smoothing polynomial filter. Rooted in least squares polynomial smoothing, its objective is to utilize the subset of the data contained in a window to find a value that is smoothed for each point in the spectrum. Each window consists of the point to be smoothed positioned at the center, along with its neighbouring values at either side of the spectrum (Savitzky and Golay, 1964). The advantage of using this filter is its ability to keep distortions to a minimum, unlike other methods such as the Moving Average Filter.

The smoothed spectral data has been used as a basis for the creation of training pixels along with the generated indices.

2.2.3 Generation of Indices: Floating debris was identified on a subpixel scale using the Floating Debris Index (FDI).

$$
F D I=R_{r S, N I R}-R_{r s, N I R}^{\prime}
$$

$R_{r s, N I R}^{\prime}=R_{r S, R E 2}+\left(R_{r s, S W I R 1}-R_{r s, R E 2}\right) \times \frac{\left(\lambda_{N I R}-\lambda_{R E D}\right)}{\left(\lambda_{S W I R 1}-\lambda_{R E D}\right)} \times 10$ 
Eq. (1) was developed by Biermann, et al. (2020) based on the Floating Algae Index (FAI). MSI Red Edge (RE) band was used instead of the red band. Hu (2009) pointed out that subtracting the baseline NIR $\left(R_{r s, N I R}^{\prime}\right)$ from the NIR $\left(R_{r S, N I R}\right)$ will permit the detection of floating debris despite having a thin layer of cloud since this process lessens the change of atmosphere sensitivity.

The Normalized Vegetation Index (NDVI) was used simultaneously to separate the plastics from floating vegetation such as seaweed:

$$
N D V I=\frac{\left(R_{r s, N I R}-R_{r s, R E D}\right)}{\left(R_{r s, N I R}+R_{r s, R E D}\right)}
$$

In Biermann et al. (2020), FDI was applied to detect pixels containing plastic targets deployed in Mytilene, Greece. The spectral signature of plastic was generated from the mean of the pixels containing the detected plastics. The same process was done for other materials commonly found among the floating marine debris. These generated spectral signatures were used as a representative to estimate other suspected plastics in Manila Bay.

Another index effective in identifying plastic was developed by Themistocleous et al. (2020). This is the Plastic Index (PI) and was applied to Sentinel 2 images that were not corrected. Bands 4 (red) and 8 (NIR) of Sentinel 2 were used in the PI formula indicated below.

$$
P I=\frac{R_{r s, N I R}}{R_{r s, R e d}+R_{r s, N I R}}
$$

2.2.4 Analysis of Indices: The values for each generated index were analysed to separate the plastics from other materials. Through the utilization of the raster calculator, the reflectance values for Band 11 with $2202 \mathrm{~nm}$ as central wavelength showed potential plastics floating on the water. After the analysis of the index maps for the Normal Vegetation Difference Index, Floating Debris Index, and Plastic Index, a decision tree was constructed.

2.2.5 Image Classification: The Naive Bayes algorithm was used to further classify the suspected floating marine debris into plastics and other materials commonly found in the debris. This model was generated using a code to classify the probability of a pixel belonging to a certain class. A confusion matrix will be used to assess its accuracy. According to Humboldt State University (2019), a confusion matrix contains different information such as the overall accuracy, different error types, and accuracy statics. In the confusion matrix, the training data were compared against the classified data. The overall accuracy gave the percentage of pixels which were classified correctly. Errors of omission and commission were also displayed in the confusion matrix. These errors show the percentage of pixels which were incorrectly classified into other categories instead of its true classification (Congalton and Green, 2008, p. 58).

Another algorithm that was used in identifying plastics from the debris is the Mixture Tuned Matched Filtering (MTMF). This algorithm was also tested since it can identify a known target without having a background or information on other endmember signatures (Boardman, 1995). Using this technique, the spectral signature of the known end-members selected during the pixel training were used to estimate how likely each pixel matched the provided classes.
This method was conducted in two phases, the Match Filter Phase and the Mixture Tuning Phase. (Research Systems Inc., 2004, p. 786-787). The first phase resulted in the Matched Filter Image, which is a gray-scale image with values that indicate the match of each pixel per class. Another image produced is the Infeasibility image, where false-positives were detected. This means that 2 images were produced for each class. Using a scatter plot, with values of the MF Score on the x-axis and infeasibility values on the $y$-axis were analysed. Pixel values with high values and Low Infeasibility values were selected as the most probable plastics. The threshold for selecting the appropriate MF score and infeasibility values were based on the mean and standard deviation of the training pixels from the resulting 2 images.

\section{RESULTS AND DISCUSSION}

\subsection{Spectral Library}

The spectral library from Project MapABLE was used as a basis for the reflectance values. The raw spectral values were smoothed using the Savitzky-Golay filter with point window value of 7 and polynomial order of 5 . The values for each Sentinel 2 band located in the NIR to SWIR region were analyzed and compared to identify which pixel values correspond to the spectral library.

\subsection{Indices Threshold}

Table 2 shows the threshold values used for the selection of training data for plastic and water.

\begin{tabular}{|c|c|c|c|c|}
\hline \multirow{2}{*}{ Index } & \multicolumn{2}{|c|}{ Plastic } & \multicolumn{2}{c|}{ Water } \\
\cline { 2 - 5 } & Minimum & Maximum & Minimum & Maximum \\
\hline NDVI & -0.145 & -0.144 & $\begin{array}{c}\text { negative } \\
\text { values }\end{array}$ & -0.145 \\
\hline FDI & -0.06 & 0.01 & 0 & 0.05 \\
\hline PI & 0.47 & 0.61 & 0.35 & 0.42 \\
\hline
\end{tabular}

Table 2. Threshold values for the plastic and water class training data selection

After the classification, the confusion matrix was generated. A confusion matrix or otherwise called an Error Matrix shows how the classification image corresponds with the reference image. The non-diagonal elements of the matrix which are the user accuracy and producer accuracy characterise the amount of errors of omission and errors of commission respectively (Ukrainski, 2016).

\subsection{Image Classification}

3.3.1 Naïve Bayes Classification: The training data resulting from the analysis of indices was used for the Naive Bayes Classification. From Fig. 4, it can be observed that the southern part of the area, an area where some of the fishing vessels dock, was classified as a built-up class for March 28, 2020. However, for the remaining five other dates, the area has been classified under the plastic class. For the dates of October 5, 2019, January 28, 2020, May 7 and 22, 2020, some pixels were classified as vegetation. For the eastern part of the area where the harbour is located, it can be observed that there were some built up classifications. This may be attributed to the ships docked in that area for the specific sensing date. There are also some pixels classified as vegetation for the BASECO lagoon and the northernmost part of the map due to the presence of water hyacinths. Some mangroves were also seen thriving at the BASECO lagoon which has been verified through the historical 
imagery of the study area. Errors of commission indicate data that were classified in a category but actually do not belong to that classification. On the other hand, omission errors occur when values that belong to a certain category are classified to another. The producer and user accuracies were created to represent the accuracy of individual classes, rather than just providing the overall accuracy which indicates only the correctly classified data. (Congalton and Green, 2008, p. 58). The producer's accuracy indicates how probable it is that a value in a class is classified correctly whereas the user's accuracy indicates the probability that the value in a class is actually in that class in the reference image. (Research Systems, Inc., 2004, p. 639) Fig. 4 shows the Naive Bayes Classification results for the different satellite image dates.

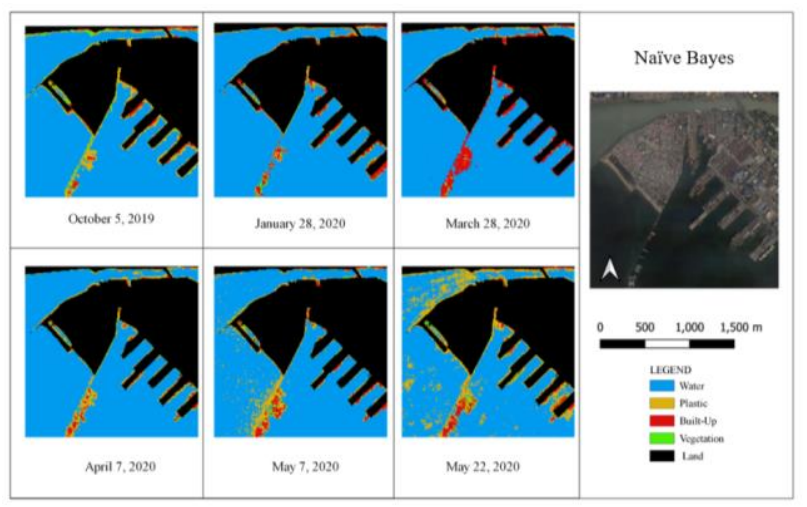

Figure 4. Resulting classification maps for all satellite images using the Naive Bayes Algorithm.

The classification results for the accuracy for each respective satellite image date's plastic class are summarized in Table 3. It can be observed that the lowest producer accuracy was for the May 22, 2020 sensing date with the value of $95.65 \%$. It can be observed however that the other five satellite images have a producer accuracy above $90 \%$. Meanwhile, January 28, 2020 and March 28, 2020 exhibited the least value for the user accuracy at 25\%. The October 5, 2019 sensing date shows us the highest value of user accuracy at $57.14 \%$.

3.3.2 Mixture Tuned Matched Filtering: ENVI software was used to process MTMF classification on all satellite images. Vector training data was converted to Regions of Interest. Spectral data from those regions were used as an input to have a user supplied end-member collection. Using the MTMF algorithm, a raster was produced, with each band showing the match filter score (MF score) and infeasibility values for each class. Since there are 4 classes, all MTMF images were composed of 8 bands. The spectral data for each resulting MTMF raster can be viewed using the metadata. It is important to note the band number and its assigned band name for raster calculations.

A 2D scatter plot was generated for the plastic class, with match score shown in the $\mathrm{x}$-axis and infeasibility in the y-axis. An example plot for the image dated October 5, 2019 is shown below in Fig. 5.

\begin{tabular}{|c|c|c|c|c|c|}
\hline Sensing Date & Class & $\begin{array}{c}\text { Producer } \\
\text { Accuracy } \\
(\%)\end{array}$ & $\begin{array}{c}\text { User } \\
\text { Accuracy }(\%)\end{array}$ & $\begin{array}{c}\text { Omission } \\
\text { Error }(\%)\end{array}$ & $\begin{array}{c}\text { Commission } \\
\text { Error (\%) }\end{array}$ \\
\hline October 5, 2019 & Plastic & 100 & 57.14 & 0 & 42.86 \\
\hline January 28, 2020 & Plastic & 100 & 25 & 0 & 75 \\
\hline March 28, 2020 & Plastic & 100 & 25 & 0 & 75 \\
\hline April 7, 2020 & Plastic & 100 & 42.55 & 0 & 57.45 \\
\hline May 7, 2020 & Plastic & 100 & 42.50 & 0 & 57.50 \\
\hline May 22, 2020 & Plastic & 95.65 & 30.99 & 4.35 & 69.01 \\
\hline
\end{tabular}

Table 3. Summary for Plastic Class Accuracy

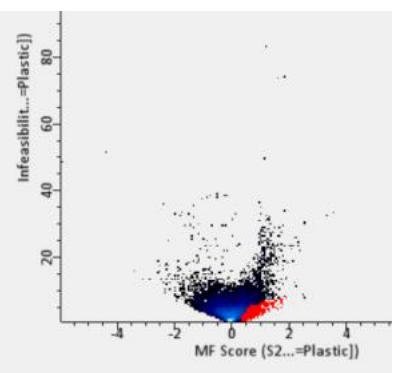

Figure 5. Values of high Matched Filtering (MF) Score and low Infeasibility (indicated by red dots) for Plastic Class of October 5, 2019 Satellite Image.

The usual method of analyzing MTMF classification is to select an area of high MF score and low infeasibility and visually analyze them. The region colored in red in Fig. 5 is an example that contains data values that have high MF score and low infeasibility. However, according to Routh et al (2018), this method could be subjective, as the user would be the one to select the appropriate values for the MF score and Infeasibility in a scatterplot. As an alternative, the summary statistics of the plastics used as training pixels were analyzed. Fifteen (15) training pixels for the plastic class were created for each image date. The Match Filter Score and Infeasibility values of these plastic pixels were inspected using the Spectral Profile Tool in QGIS. The mean and standard deviation of the plastic pixels were computed. These statistics were used to find other pixel values from the MTMF raster which are lying in the same range. Table 4 below shows the range of values for MF score and Infeasibility for each satellite image date.

\begin{tabular}{|c|c|c|c|c|c|c|c|c|}
\hline & \multicolumn{3}{|c|}{ Band 2 (MF Score of Plastic) } & \multicolumn{3}{c|}{ Band 6 (Infeasibility of Plastic) } \\
\hline Date & Average & $\begin{array}{c}\text { Standard } \\
\text { Deviation }\end{array}$ & Minimum & Maximum & Average & $\begin{array}{c}\text { Standard } \\
\text { Deviation }\end{array}$ & Minimum & Maximum \\
\hline $\begin{array}{c}\text { Oct 5, } \\
2019\end{array}$ & 1.000 & 0.460 & 0.540 & 1.460 & 5.113 & 1.580 & 3.533 & 6.693 \\
\hline $\begin{array}{c}\text { Apr 7, } \\
2020\end{array}$ & 0.917 & 0.538 & 0.379 & 1.455 & 4.696 & 1.414 & 3.282 & 6.111 \\
\hline $\begin{array}{c}\text { Jan 28, } \\
2020\end{array}$ & 0.915 & 0.402 & 0.514 & 1.317 & 3.517 & 1.839 & 1.679 & 5.356 \\
\hline $\begin{array}{c}\text { Mar 28, } \\
2020\end{array}$ & 0.936 & 0.443 & 0.493 & 1.378 & 4.216 & 1.788 & 2.428 & 6.005 \\
\hline $\begin{array}{c}\text { May 7, } \\
2020\end{array}$ & 1.010 & 1.033 & -0.022 & 2.043 & 3.638 & 1.557 & 2.081 & 5.195 \\
\hline $\begin{array}{c}\text { May 22, } \\
2020\end{array}$ & 1.000 & 0.438 & 0.562 & 1.438 & 3.847 & 1.765 & 2.082 & 5.612 \\
\hline
\end{tabular}

Table 4. Statistical measures summarizing the 15 training pixels for each image date.

Raster calculation was used to find other pixels lying in the calculated range of values. Fig. 6 shows the plastics identified by the MTMF classification methods.

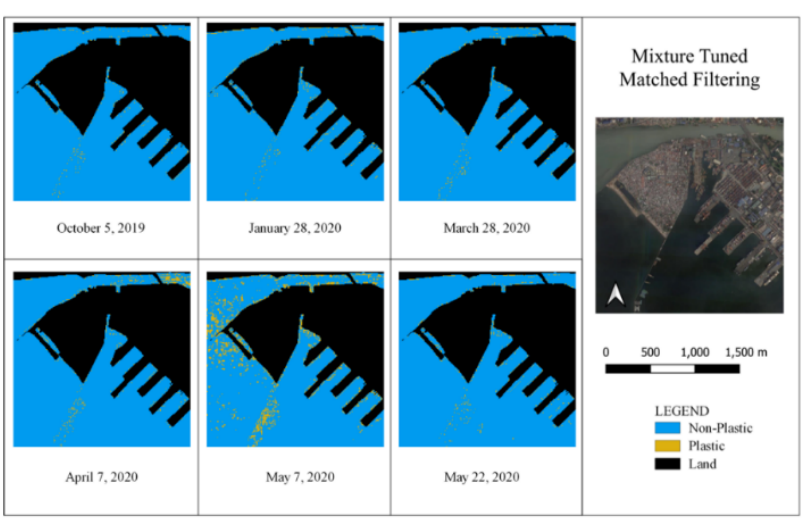

Figure 6. Mixture Tuned Matched Filtering result for plastics. 
Since the output of MTMF are specified by the infeasibility and MF score values of the specified class, pixels whose values are 0 are depicted in blue to denote the water area.

The same process was repeated for other classes on all satellite image dates. MF Score and Infeasibility values were extracted from the appropriate training data per class. Summary statistics were used as threshold values to select other points within the image.

\subsection{Comparison of the Two Classification Methods}

The direct results of the MTMF classification are Infeasibility and Match Filter Images, not a classification map like Naive Bayes. However, for the purpose of comparing the 2 classification methods, other classes were also identified in the MTMF using threshold values in order to produce a map similar to Naive Bayes.

It is important to note that the identified pixels per class are selected based on the threshold values derived from the training data. As a result, there are unclassified pixels. This is unlike the classification map of Naive Bayes method, which does not have unclassified pixels since it automatically assigns a pixel to a class that it has the highest probability of belonging to. For this research, the MTMF classification method is dependent on the threshold values derived from the training data. The training data for the Built-up and Vegetation were identified manually, unlike Plastic training pixels, which were based on the analysis of field spectral data and generated indices. The values of Built-up and Vegetation have high standard deviation. Meaning, there is a high dispersion from the mean value, which supposedly is the nearest to the actual value of the class. There is a need to further investigate other methods on identifying more appropriate threshold values to avoid misclassification.

Visually analysing the classified plastic pixels in both methods, one can see that Naive Bayes identified more plastics than the MTMF. This may be due to the Infeasibility images of MTMF, which reduces the number of falsely classified plastics or the false-positives. Fig. 7 shows the comparison of the generated map after analysing which pixels were classified as plastics by Naive Bayes Classification but were not classified as such in the Mixture Tuned Matched Filtering Classification. Through the infeasibility image of the Plastic from the MTMF, we could see that the bright pixels depict high infeasibility values which would explain why in the MTMF classification, these pixels were not classified as plastics.

\subsection{Overlap of the Two Classification Results}

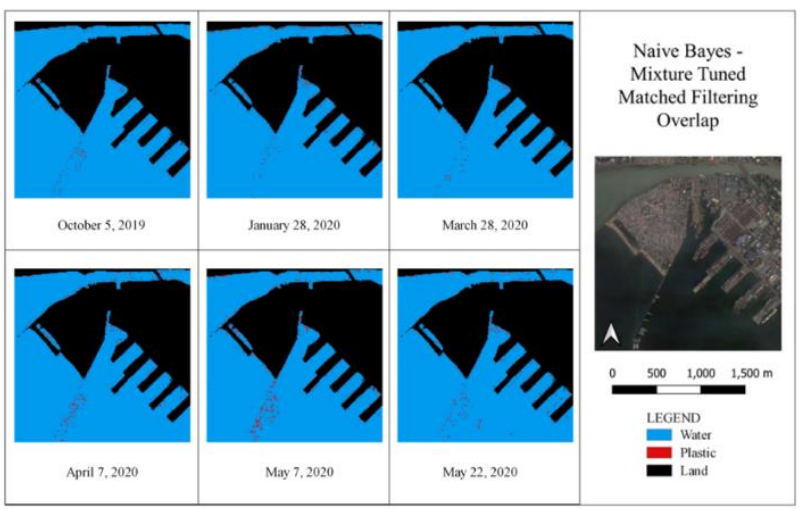

Figure 7. Overlap of Naive Bayes and Mixture Tuned Matched Filtering Classification results.
All pixels classified as plastic in both Naive Bayes and MTMF for each satellite image date are shown in Fig. 7. Raster calculator was used to find the overlap with the plastics identified in the MTMF and Naive Bayes raster. Land mask was used to highlight the floating plastics, which is the subject of the study.

\subsection{Validation}

For the validation, various reports and articles from Philippine Government Agencies have been utilized to verify the location of plastics that may accumulate at different areas around the study area.

According to a January to October 2019 Manila Bay Cleanup update report by Metropolitan Manila Development Authority (MMDA), daily clean-up operations are conducted in October 2019 at BASECO's Lagoon, Lagoon Mouth, Aplaya Side, and Beach Area as indicated in Fig. 8 below.

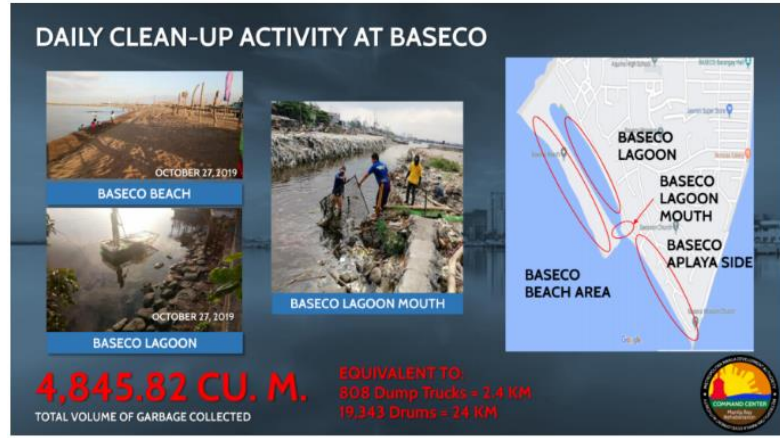

Figure 8. Clean-up Activity Update from MMDA website.

A total of 4,845.82 cu.m. of garbage was collected. The location identified by MMDA was compared to the overlap of the two classifications used. It can be observed in Fig. 9 that some of the identified plastic pixels from the methodology have the same location as reported by MMDA.

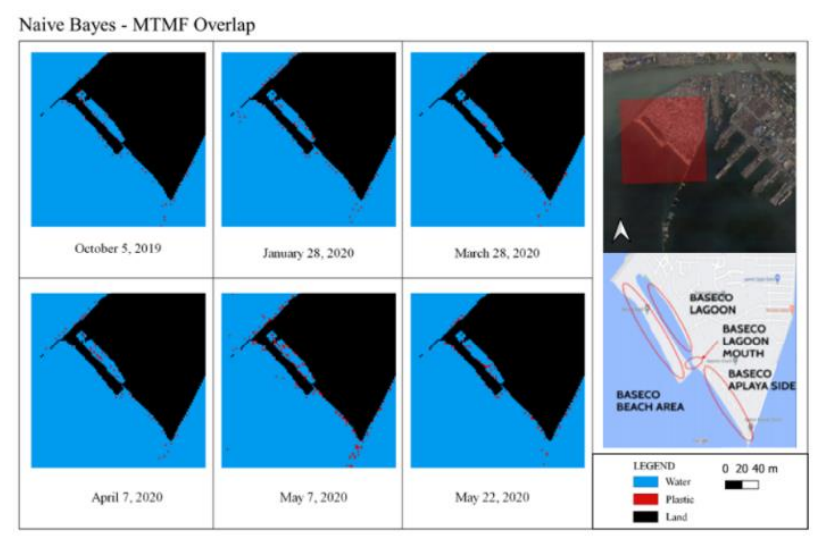

Figure 9. Comparison of the overlap with the reported location of MMDA

Another report from the website of MMDA on the Manila Bay rehabilitation program in 2019 indicated that 2,594.34 cubic meters or 737.12 tons of garbage and water hyacinth were removed from the same areas mentioned above. This was dated January 7 to August 31 . According to the report, plastics are one of the many types of garbage that was thrown into esteros and creeks and carried by the current.

PRRC Environmental Management Division Head Merliza Bonga indicated in 2018 that Pasig River is expected to be more polluted during the dry season since its flow is reversed, causing 
the floating garbage and other suspended solids to be flown back to the direction of Laguna de Bay.

According to DENR in 2019, part of their clean-up efforts is to relocate around 100,000 informal settlers residing at BASECO Compound since these dwellers contribute to the pollution. Fig. 10 shows the trash that can be found on the beach side of BASECO area which shows some of the residents utilizing the bay despite the pollution. A total of 8 drone inspections conducted by MMDA in June 2019 showed that the trash accumulated at the BASECO lagoon mouth and BASECO's northern part as seen in Fig. 11.

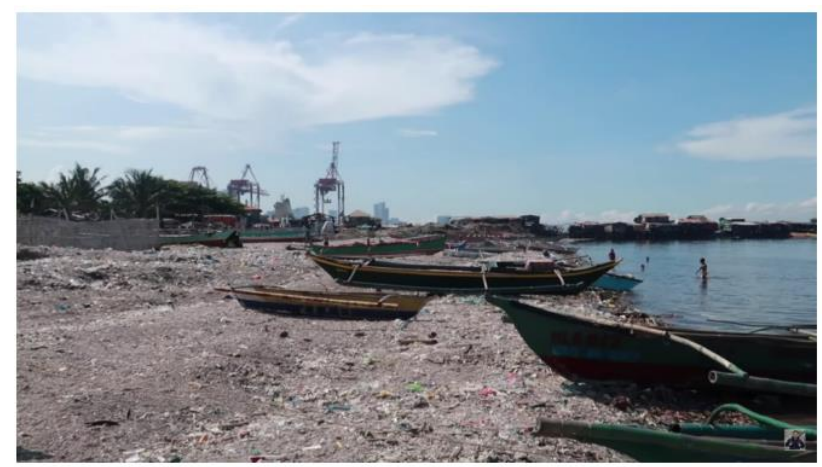

Figure 10. Trash mixed with the sand in BASECO beach area.

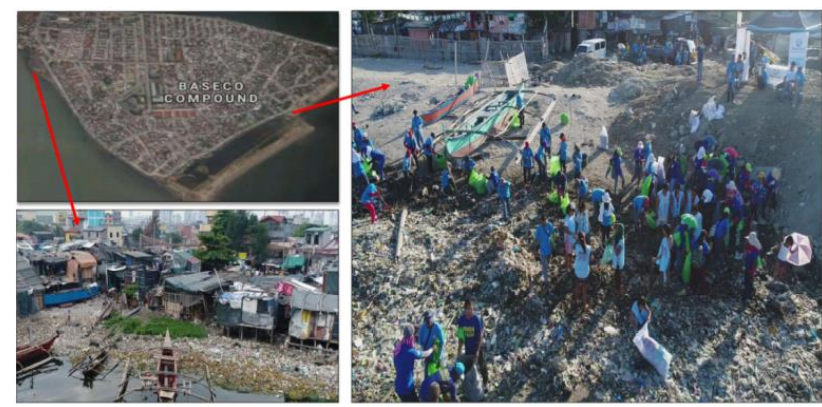

Figure 11. Drone inspections at trash accumulation points in the BASECO area.

Since the start of January 2020, members of the Department of Public Services Baseco Beach Warriors have been collecting trash along the stretch of BASECO Beach. By September 2020, the cumulative amount of trash that they have collected is around 163 metric tons of garbage (Tiangco, 2020).
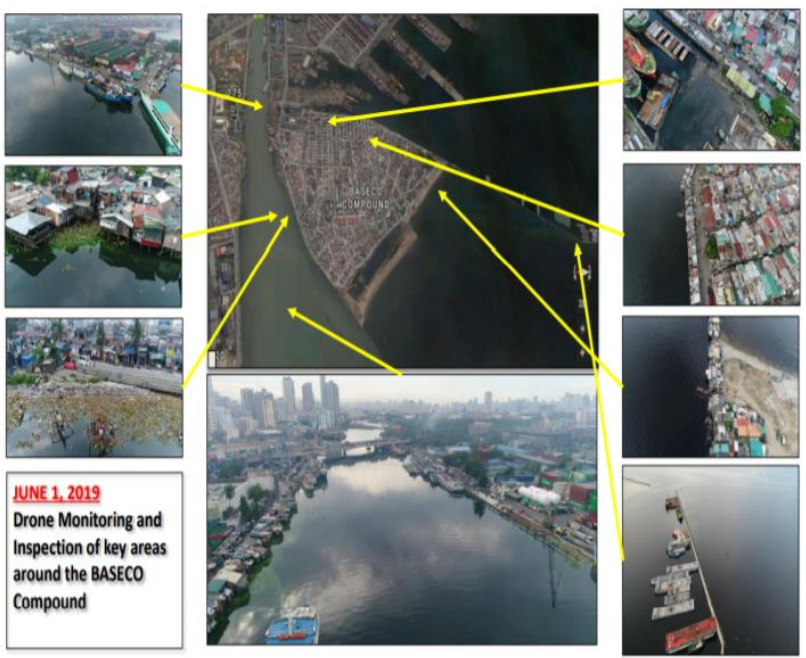

Figure 12. Drone Monitoring of Key Areas in BASECO area by MMDA.
Overall, clean-up activities are usually conducted at BASECO's Lagoon, Lagoon Mouth, Aplaya Side, and Beach Area since this is where trash accumulates. This validates the result of the classification images, since plastic pixels are also identified in the same areas. From Fig. 12, it can be seen that some trash also accumulates at the northern part of the BASECO area. Comparing the results of the overlap of the two supervised classifications, there were some plastic pixels that were classified along this area.

\section{CONCLUSION AND RECOMMENDATIONS}

The utilization of Sentinel-2 image showed that the methodology presented in this research has the potential to estimate the plastic found in the study area. With all of the limitations in mind and other factors that may affect the result, the Naive Bayes Classification showed that it was able to estimate more potential plastic pixels. The Mixture Tuned Matched Filtering classification method has also shown its capability to estimate plastics. The Match Score Images helped in estimating which pixels most likely contain plastics while the Infeasibility Images helped reduce the number of false positives.

Since the two methods used are both supervised classification methods, they are highly dependent on the user-supplied training samples. However, the accuracy of the training data used may be affected due to the limitations of not being able to physically visit the study area and take in-situ measurements. Some other possible errors may also be attributed to the water quality of the seawater and the weather during the sensing date.

It is highly recommended to undergo a field work wherein plastic targets will be placed on various locations to see how plastics are really observed from the satellite and how it behaves upon the satellite overpass which will then serve as the control data. A separate field work may also be performed for validation. This involves physically checking the locations and observing whether these locations accumulate trash frequently. Future studies may also include the utilization of a high-resolution imagery to further validate the results from the methodologies used. More studies on the different types of plastic found in Manila Bay and further analysis on their spectral signature may also be done to expand the spectral library. Applying the methodology for satellite images with an equal time interval and a span of more than one year for further observations is highly encouraged, if the weather and instruments permit, to produce more representative values. Lastly, the use of Synthetic Aperture Radar (SAR) images to see whether these images have the potential to estimate plastics floating on the water as an alternative to Sentinel-2 may also be explored as well.

\section{REFERENCES}

American Chemical Society, 1993. National Historic Chemical Landmarks. Bakelite: First Synthetic Plastic. Retrieved from https://www.acs.org/content/acs/en/education/whatischemistry/l andmarks/bakelite.html

Biermann, L., Clewley, D., Martinez-Vicente, V. et al., 2020. Finding Plastic Patches in Coastal Waters using Optical Satellite Data. Sci Rep 10, 5364. https://doi.org/10.1038/s41598-02062298-z.

Boardman, J., et al., 1995. Mapping Target Signatures Via Partial Unmixing of AVIRIS Data. Summaries Proceedings of the Fifth JPL Airborne Earth Science Workshop, Pasadena, 23-26, 95-101. 
Congalton, R. and Green, K., 2019. Assessing the Accuracy of Remotely Sensed Data. Third edition. CRC Press.

Garaba, S. P., \& Dierssen, H. M., 2018. An airborne remote sensing case study of synthetic hydrocarbon detection using short wave infrared absorption features identified from marineharvested macro- and microplastics. Remote Sensing of Environment, 205, 224-235.

Goddijn-Murphy, L., et al., 2018. Concept for a hyperspectral remote sensing algorithm for floating marine macro plastics. Doi: 10.1016/j.marpolbul.2017.11.011

Hu, C., 2009. A novel ocean color index to detect floating algae in the global oceans. Remote Sensing of Environment. 113.21182129. 10.1016/j.rse.2009.05.012.

Humboldt State University, 2019. Accuracy Metrics. Introduction to Remote Sensing. Retrieved from http://gsp.humboldt.edu/olm_2019/courses/GSP_216_Online/le sson6-2/metrics.html

Jambeck, J. R., Geyer, R., Wilcox, C., Siegler, T. R., Perryman, M., Andrady, A., Law, K. L., 2015. Plastic waste inputs from land into the ocean. Science, 347(6223),768- 771.

Jain, S.K. \& Singh, V.P., 2003. Developments in Water Science. Elsevier. //doi.org/10.1016/S0167-5648(03)80057-6.

Kou, L., Labrie, D., and Chylek, P., 1993. Refractive indices of water and ice in the $0.65-2.5 \mu \mathrm{m}$ spectral range. Appl. Opt. $32: 3531-3540$.

Kukreja, R., 2020. What is Ocean Pollution?. Conserve Energy Future. Retrieved from https://www.conserve-energyfuture.com/causes-and-effects-of-ocean-pollution.php

Research Systems Inc., 2004. ENVI User Guide. Mixture Tuned Matched Filtering.

Lebreton, L., van der Zwet, J., Damsteeg, JW. et al. 2017. River plastic emissions to the world's oceans. Nat Commun 8, 15611. https://doi.org/10.1038/ncomms15611.

Manila Bay Environmental Management Project, 2002. Manila Bay Coastal Strategy. Overview of Manila Bay. Retrieved from http://119.92.161.2/mbemp/dloads/mbcs\%2002mvw.pdf

Mercado, R. M., 2016. People's Risk Perceptions and Responses to Climate Change and Natural Disasters in BASECO Compound, Manila, Philippines. Procedia Environmental Sciences, 34, 490-505. doi:10.1016/j.proenv.2016.04.043.

Moroni, M., Mei, A., Leonardi, A., Lupo, E., La Marca, F., 2015. PET and PVC Separation with Hyperspectral Imagery. Sensors 2015, 15(1), 2205-2227; https://doi.org/10.3390/s150102205.

National Government Portal, 2019. Manila Bay Cleanup Operations Yield 3,810 Tons of Garbage. Retrieved from https://mmda.gov.ph/54-news/news-2019/4101-sept-9-2019manila-bay-cleanup-operations-yield-3-810-tons-ofgarbage.html

National Government Portal, 2019. Manila Bay Cleanup Update January to October $2019 . \quad$ Retrieved from https://mmda.gov.ph/images/Home/Manila-

Bay/Manila_Bay_Update_Jan-_Oct_2019.pdf
National Oceanic and Atmospheric Administration, 2020. Ocean Pollution. Retrieved from http://www.noaa.gov/education /resource-collections/ocean-coasts/ocean-pollution.

Partnerships in Environmental Management for the Seas of East Asia and Manila Bay Environmental Management Project, 2001. Manila Bay Coastal Strategy. Retrieved from http://pemsea.org/publications/reports/manila-bay-coastalstrategy

Plastic Bank, 2020. Waste to Wages: Changing Narratives. Retrieved from https://plasticbank.com/waste-to-wageschanging-narratives/

Philippine Astronomic, Geophysical and Astronomical Services Administration, 2015. Climate of the Philippines. Retrieved from https://web.archive.org/web/20151115114718/https://kidlat.pag asa.dost.gov.ph/index.php/climate-of-the-philippines

Routh, D. \& Seegmiller, L.\& Bettigole, C. \& Kuhn, C. \& Oliver, C. \& Glick, H., 2018. Improving the Reliability of Mixture Tuned Matched Filtering Remote Sensing Classification Results Using Supervised Learning Algorithms and Cross-Validation. Remote Sensing. 10. 1675. 10.3390/rs10111675.

Ruffin, C. \& King, R., 1999. The analysis of hyperspectral data using Savitzky-Golay filtering-theoretical basis. 1. 2. $756-758$ vol.2. 10.1109/IGARSS.1999.774430.

Savitzky, A. and Golay, M. J., 1964. Smoothing and Differentiation of Data by Simplified Least Squares Procedure. Analytical Chemistry 36 (8), 1627-1639 DOI: 10.1021/ac60214a047.

Subingsubing, K., 2019. 400 truckloads of trash taken from Manila Bay since January. Retrieved from https://newsinfo.inquirer.net/1122293/400-truckloads-of-trashtaken-from-manila-bay-since-january

Themistocleous, K., et al. 2020. Investigating Detection of Floating Plastic Litter from Space Using Sentinel-2 Imagery. Remote Sens. 12(16), 2648; https://doi.org/10.3390/rs12162648.

Tiangco, M., 2020. 163 tons of garbage hauled from Baseco since January. Retrieved from https://mb.com.ph/2020/09/03/163tons-of-garbage-hauled-from-baseco-beach-since-january/

Ukrainski, P., 2016. Classification Accuracy Assessment. Confusion Matrix Method. Retrieved from http://www.50northspatial.org/classification-accuracyassessment-confusion-matrix-method/

Vanhellemont, Q., Ruddick, K., 2015. Advantages of high quality SWIR bands for ocean colour processing: Examples from Landsat-8. Remote Sensing of Environment, Volume 161, Pages 89-106. https://doi.org/10.1016/j.rse.2015.02.007.

World Ocean Review, 2010. Pollution: Litter. Living with the oceans. A report on the state of the world's oceans. Retrieved from https://worldoceanreview.com/en/wor-1/pollution/litter/.

World Vision's Waste to Wages, 2019. More than 70MT of plastic containers collected in Baseco through Waste to Wages Project. Retrieved from https://www.worldvision.org.ph /stories/baseco-waste-to-wages-project-update/ 